\title{
Developments in Variable Renewable Energy and Implications for Developing Countries
}

\author{
Channing Arndt ${ }^{1} \cdot$ Faaiqa Hartley ${ }^{2} \cdot$ Gregory Ireland $^{2} \cdot$ Kristi Mahrt $^{1} \cdot$ Bruno Merven $^{2} \cdot$ Jarrad Wright $^{3}$
}

Published online: 31 October 2018

(C) The Author(s) 2018

\begin{abstract}
Purpose of Review Significant and mainly unpredicted advances in variable renewable energy technologies are resulting in structural shifts in energy systems globally causing an energy revolution. This review focuses on the implications for developing countries including the water-energy nexus.

Recent Findings Developing countries typically feature promising endowments in renewable resources, rapidly growing demand, and a relative lack of legacy generation systems. With the costs of wind and solar dipping below their non-renewable competitors, developing countries are potentially positioned for rapid uptake of variable renewable energy systems. The South African case provides an example of strong renewable energy endowments, illustrates the benefits of detailed energy analysis for exploitation of these endowments, and shows that this combination can lead to high variable renewable energy penetration in the least cost energy mix. The energy-water nexus is highly likely to be strongly influenced by this energy revolution. For example, hydropower has the capability to play an important role in load balancing; however, it is not clear that the necessary transmission infrastructure, institutions, and international cooperation will emerge of this potential role of hydro and adjudicate across competing demands for water. Decisions in the traditional water and energy sectors are still often taken in isolation.

Summary Overall, the technological advances provide a valuable opportunity for enhancing growth and development prospects in developing countries while meeting environmental objectives at global and local scales. The implications for the energy-water nexus are frequently unclear, as planning decisions around energy and water investments are traditionally taken without using an integrated approach. Accelerated research efforts and fresh thinking to integrate modeling and planning around the supply of water and energy are key to realizing the potentials inherent in the ongoing energy revolution.
\end{abstract}

Keywords Variable renewable energy $\cdot$ System integration $\cdot$ Hydropower $\cdot$ Developing countries $\cdot$ South Africa $\cdot$ Water-energy nexus

\section{Introduction}

The global energy landscape has changed dramatically in recent years. The International Energy Agency's (IEA)

This article is part of the Topical Collection on Regional Renewable Energy - Africa

Channing Arndt

c.arndt@ cgiar.org

1 International Food Policy Research Institute, Washington, D.C., USA

2 Energy Research Centre, University of Cape Town, Cape Town, South Africa

3 Council for Scientific and Industrial Research, Pretoria, South Africa most recent report, Renewables 2017, indicates that globally in 2016, renewables accounted for nearly two-thirds of new electricity capacity additions [1]. Solar photovoltaic (PV) capacity increased by 50\% in 2016 and for the first time, solar PV additions increased faster than any other fuel.

The shift toward renewables has been driven by rapidly declining costs of variable renewable energy (VRE - a collective term for solar and wind energy) generation, which have now become cost competitive with conventional fossil fuel technologies in many contexts. The International Renewable Energy Agency (IRENA) estimates that between 2010 and 2016, average solar prices fell by a factor of about five, while the unitized capital cost of lithium-ion batteries (per $\mathrm{kWh}$ ) fell by $50 \%$ between 2014 and 2016 [2,3]. Wind generation costs have also decreased over the past 5 years with wind auction 
prices falling by a factor of about two [4]. Continued cost declines are widely expected [4-6].

This review seeks to synthesize a wide variety of work assessing the state of VRE and its potential for enhancing growth and development prospects in developing countries including implications for the energy-water nexus. The "Unexpected-Global VRE Costs and Capacity Additions" section briefly summarizes global VRE trends, including comparisons to projections highlighting the unexpected nature of the cost declines (by major agencies) and associated failure to predict capacity changes. The "Barriers to Adopting Renewable Energy" section discusses barriers to substantial reliance on VRE in developing countries' generation mixes and the potential role of hydropower in meeting this challenge. The "Renewable Energy Potential and System Integration in South Africa" section provides a case study of South Africa. The "Discussion Including Implications for the Energy-Water-Food Nexus" section highlights key questions and related analytical needs and discusses the energy-water nexus.

\section{Unexpected-Global VRE Costs and Capacity Additions}

For many years, the US Energy Information Agency's (EIA) and the International Energy Agency's (IEA) projected contributions of wind and solar to the electric power sector have greatly missed the mark. Both agencies have been subject to criticism for their inability to anticipate falling costs as well as mounting political and social momentum which have bolstered growth in solar and wind [7-12]. Over the past 10 years, each agency's annual reports have repeatedly failed to predict the extent of solar and wind growth.

This phenomenon is illustrated in Fig. 1, which displays actual and projected utility-scale solar PV levelized cost of energy (LCOE) estimates. ${ }^{1}$ The EIA line displays the projections for the labeled year, which are reported on the horizontal axis. For example, there are two points on the solid black line labeled 2016. The first point reflects the EIA projected LCOE for 2016 in 2010 while the second point reflects the 2011 projection. EIA projected LCOEs are reported alongside Lazard, IEA, and IRENA current year estimates to illustrate

\footnotetext{
${ }^{1}$ LCOE estimates the average total cost per total energy output of constructing and operating an electricity generating facility over its lifetime. For the purposes of this study, LCOE provides a useful means of comparing the relative cost of different generating technologies. However, it is important to note that LCOE is not always the most accurate tool for comparing technologies with very different characteristics. To fully understand the implications of the advances in energy technologies on future electricity generation, a fully integrated energy systems assessment is required. LCOE values also reflect numerous parameter choices and assumptions across various technologies. As such, these levels are not strictly comparable between studies, but nonetheless provide a tool for assessing patterns and trends.
}

trends in expected costs relative to the current cost environment. Projections into the near future have been roughly in line with current costs but projected LCOEs have been consistently and substantially above realized levels. In this context, it is noteworthy that the most recent projections to 2022 once again posit no further declines from observed cost levels.

In line with cost declines and attainment of cost levels competitive in many contexts with traditional generation sources, installed PV capacity has increased significantly since 2005. These rapid increases in PV capacity have been, until very recently, consistently under-captured in projections by the EIA and the IEA (see [13] for a comprehensive comparison). The EIA and IEA are not the only organizations who have fallen short in their forecasts. According to REN21, even the solar industry's own early projections have been surpassed by the actual uptake [14].

Two points are worth highlighting. First, the degree of projection error has been large. For example, actual utility-scale solar installations in 2016 exceeded projected installations for 2030 made in the Annual Energy Outlook 2015 (AEO 2015). Second, these lower costs are spilling over to developing countries. This is illustrated by the South African experience. Since 2011, 6328 MW of renewable capacity has been procured through South Africa's Renewable Energy Independent Power Producer Procurement Programme (REIPPPP) with construction underway for a large proportion of this capacity [15]. While South Africa's prices were relatively high at the start of the REIPPPP, prices fell dramatically over the competitive bid rounds, particularly for solar PV in line with international technology trends. The cost of solar PV decreased by more than $80 \%$ between 2011 and 2015 while the cost of wind decreased by almost $60 \%$ [13]. As will be seen, these advances have resulted in renewable technologies being cost competitive with new coal independent power producers (IPPs) as well as new builds [13].

At this moment in time, there is a high potential for renewable energy systems to move rapidly into developing country settings. As will be discussed in detail below for South Africa, developing countries are often well endowed with renewable resources. Many also feature rapidly growing energy demand combined with a relative lack of legacy energy systems. Nevertheless, taking advantage of low-cost VRE systems is not simple, particularly for centralized generation at scale to meet demand in metropolitan areas. These barriers to adoption are described further in the next section.

\section{Barriers to Adopting Renewable Energy}

The greatest barriers to adopting VRE at scale are no longer modular costs but the technical, institutional, policy, and market adjustments required to incorporate renewable energy, and particularly VRE, cost-effectively into an electricity system. 
Fig. 1 Actual and projected solar PV LCOE, 2009-2017 (2015 \$/MWh). Sources: EIA. 2016 Levelized Cost of New

Generation Resources from the Annual Energy Outlook 2010. Washington D.C.: U.S. Energy Information Administration. 2010, 2012-2017.; Lazard. Lazard's Levelized Cost of Energy Analysis - Version 10.0. New York: Lazard. 2016.; IEA [22]; IRENA [18]. Note: EIA (AEO) LCOE values are projections reported in each year on the horizontal axis for the labeled year

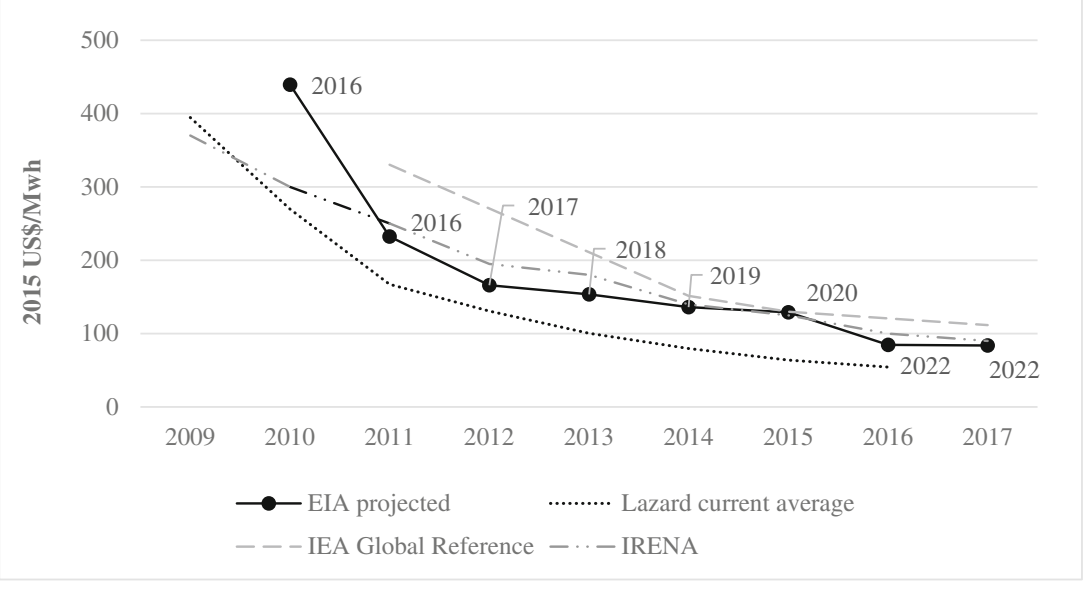

These challenges are collectively referred to as system integration. Among the most prominent of these challenges is the variable and not fully predictable nature of VRE coupled with the need to balance electricity supply and consumption at all times.

However, system integration knowhow and equipment such as batteries and flexible resources such as distributed resource aggregators (DRA) are improving, and experience is being gained in countries like Denmark where VRE currently approaches $50 \%$ of total generating capacity [16]. A considerable reserve of both technical and policy best practices is emerging. For instance, IRENA identifies key planning stages and provides guidelines for short- and long-term planning targets for systems aiming to scale up to high shares of VRE [17]. Capitalizing on this knowledge is essential to reduce integration costs and fully capture the advantages of wind and solar [16-22].

The process of integrating VRE into the electricity generation mix depends on multiple factors specific to each generation system including geography, existing infrastructure, available technologies for generation and storage, the institutional and regulatory climate, local knowledge, the ability to make use of resources such as DRA, and the capacity to operate and maintain these systems. Challenges to integration mainly stem from not having in place more flexible systems to accommodate the cheaper but less predictable and variable RE resource. The challenges generally mount as the share of electricity generated from VRE grows, especially without an enabling environment driven by the right policies and tariff mechanisms. Ultimately, as VRE becomes a primary generation source, integration requires a comprehensive and systematic approach.

Integration is easiest when the availability of VRE corresponds to demand both diurnally and seasonally. While resources situated far from demand centers require greater transmission costs, systems spread over large geographical areas also help mitigate issues with, for example, cloud cover by reducing the probability that all systems are impacted by cloud cover simultaneously. Larger systems-achievable through intersystem and interregional cooperation - can achieve a portfolio effect of more stable generation via greater geographical diversity.

There is also a revised role for hydropower with reservoirs. Within the context of traditional systems with a substantial thermal generation component and hydropower, the typically very low marginal cost of hydropower generation implied a limited role for hydropower in load balancing. Under a system with substantial VRE penetration, the ability to switch on and off turbines in accordance with variations in renewable outputs becomes a critical feature. With an ability to modulate output from the reservoir, the hydropower generated arrives at high value times when outputs from VRE are low. Without an ability to modulate hydropower output, the burden of adjustment must be passed to other elements of the system. Analyses in Africa indicate a high upside for integrating hydropower and VRE [23, 24].

In addition to hydropower, flexibility of conventional fuel technology in terms of start-up times, minimum load, and ramping speed also facilitates greater VRE adoption. Natural gas combustion turbines and internal combustion engines provide the most flexibility while coal and nuclear units are among the least flexible. In addition to flexible generation, system flexibility can also be achieved via storage, demandside flexibility, interregional coordination, well-coordinated institutional arrangements, and operational practice/ technology $[17,25]$.

Another potential source of flexibility in water scarce regions is the use of water desalination plants and balancing loads, potentially avoiding curtailment of excess VRE power. It is cheaper to store water than electricity, so diverting excess power to desalination plant improves the efficiency of the overall energy-water supply system. 


\section{Renewable Energy Potential and System Integration in South Africa}

South Africa has undertaken some of the most detailed assessments of their energy resources and system integration possibilities on the African continent to date. Even though the South African economy and electricity systems differ substantially from most other African countries, South African endowments and system integration considerations provide relevant insights to other developing countries. Hence, we focus on South Africa here.

South Africa possesses some of the best solar and wind resources in the world. For example, a PV project at a typical location in South Africa generates almost twice as much energy as the same project in Germany [13]. Vast areas of South Africa are suitable for generating electricity at low cost from renewable energy using solar PV, concentrated solar power (CSP), and wind technologies [26-29].

Recent studies have also shown that South African wind resources are significantly greater than previously estimated with inland resources being even greater than the previously known high resource sites along the coast. The Council for Scientific and Industrial Research (CSIR) and Fraunhofer [29] extended the existing work done by the Wind Atlas of South Africa project [28] and showed that between $55 \%$ and $65 \%$ of South Africa's land area has technically recoverable wind capacity exceeding a $35 \%$ load factor (totaling $\sim 3500$ $4500 \mathrm{GW}$ and $\sim 11,500-14,500 \mathrm{TWh} / \mathrm{a}$ ). The geographic spread of the resources is a distinct advantage permitting a generation portfolio effect across high potential sites. Once again, this wind endowment is much better than the endowment for Germany where high potential areas are offshore and concentrated in the northeast [13].

Wind and solar PV aggregation research undertaken in [28] characterizes wind and solar PV power profiles for South Africa. Their findings for the grid-focused scenario show that wind and solar PV profiles had annual capacity factors of $36 \%$ and $20.4 \%$, respectively [30 $]$. Usefully for South Africa, combined solar and wind resources are highly complementary, with the combination of their typical daily outputs matching the country's electrical demand surprisingly well. Demand coverage factors range between 0.9 and 1.1 for not quite $50 \%$ of the year. Demand coverage rarely exceeds 1.3 or falls below 0.7 [13]. The portfolio effect of distributing generating resources across the country contributes substantially to this stability [29, 31].

The implications of the cost declines and system integration possibilities for the electricity generation mix to 2050 are shown in Fig. 2. The South African TIMES Model (SATIM) is a full energy sector where energy technologies from both the supply sectors (power plants, refineries) and the demand sectors (industrial processes, transport modes, etc.) are represented. The CSIR model is a power sector Plexos Model with higher time resolution that SATIM. The NREL model is also a power sector model with high time resolution but also higher spatial resolution, incorporating some of the transmission network bottlenecks that exist in the South African system. Three separate studies [32••, 33•, 34] project VRE contributing 60 to $70 \%$ of total annual electricity generation around 2050 when minimizing standard economic costs with no accounting for greenhouse gas emissions or health costs related to thermal generation. The high VRE share from 2040 onward is made possible because of the ability to situate solar and wind generation in a manner that exploits the complementary resource profiles discussed above combined with the use of flexible gas generators and storage technologies in hours of low wind and solar resource availability.

It is important to highlight that, in South Africa, the legacy of existing power plants, combined with relatively slow projected demand growth, significantly delays the adoption of VRE shown in Fig. 2. VRE costs, including system integration consideration, are highly competitive with new thermal generation (capital costs plus marginal cost of operation). Therefore, in South Africa, VRE enters the mix as old thermal plants are retired. If the costs of VRE drop below the marginal cost of thermal generation (a possibility, see [35]), then substantial VRE would enter into the South African least cost generation mix sooner in time.

\section{Discussion Including Implications for the Energy-Water-Food Nexus}

Unlike South Africa, many developing countries, particularly in Africa, do not possess a substantial fleet of existing power plants, and power demand is projected to grow rapidly. For example, IEA projects demand in sub-Saharan Africa to triple by 2040 [36], though these projections are based on dated cost assumptions. With renewable technologies broadly available, the unexpected profusion of renewable systems that has occurred over the past 5 to 10 years in many developed countries as well as China has the potential to reproduce itself over the next 5 to 10 years with equal or greater force in lower income contexts such as in Africa.

Focusing on Africa, the basic building blocks of an African energy revolution are reasonably clear. There is high solar potential almost everywhere. Considerable wind potential also exists. The continent is clearly big enough to obtain a substantial portfolio effect in generation across space. Large untapped hydropower potential on the Nile, Congo, and Zambezi river basins as well as to a lesser extent on the Volta River and elsewhere enhances potential for low-cost and low-emission energy systems particularly if these hydropower systems play a load balancing role. Fossil fuel endowments, notably natural gas, are likely to be useful complements. Finally, the modular nature of solar PV systems combined with rapidly declining 
Fig. 2 Projected VRE share (wind and solar) in South Africa for a range of recent analyses. Source: Merven et al. [32••]

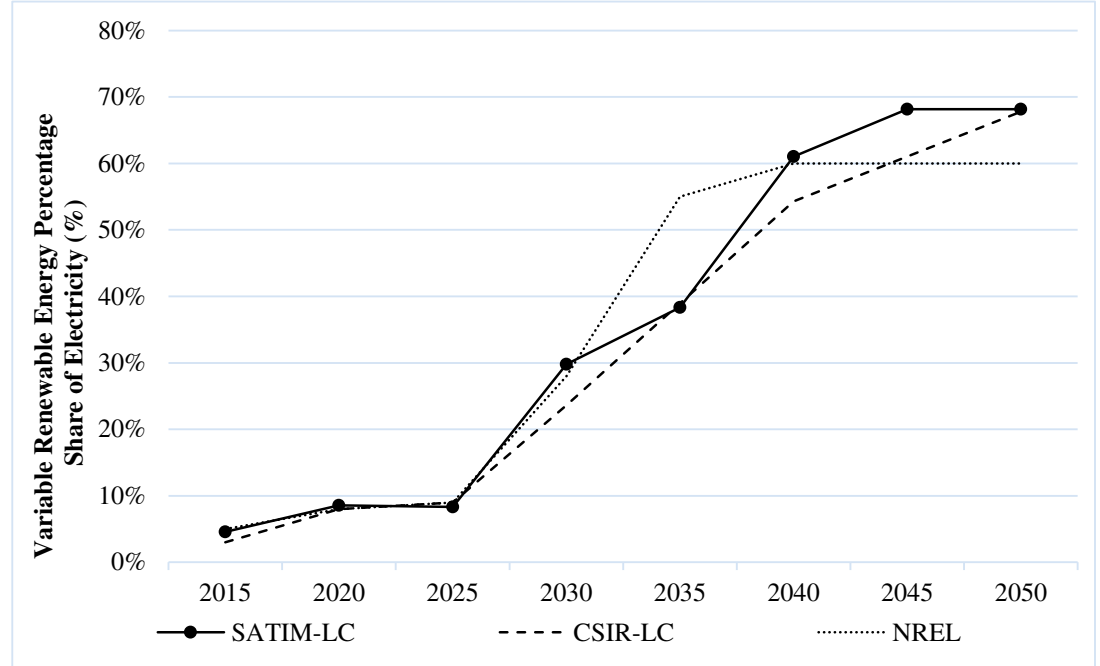

battery costs provides unprecedented opportunities for rural electrification as well as for independence from centralized generation more generally.

Overall, African countries have the potential to encounter high shares of VRE in their generation mix in short time frames. But, a great deal remains to be done to operationalize these basic building blocks such that the benefits of low cost renewables are realized and the barriers discussed in the "Barriers to Adopting Renewable Energy" section are overcome. A partial "to do" list includes the following:

- Mapping of renewable energy potential to arrive at complementary power mixes that meet expected demand profiles. As noted above, South Africa, where renewable resource data quality is relatively good, has very recently reassessed wind power potential to be more favorable.

- Consideration of the balance between centralized generation and independent mini-grids. Utility-scale solar and very large wind turbines are efficient in terms of generation, but centralized generation requires functional institutions for transmission, distribution, and load balancing.

- A revised institutional and regulatory environment. Like many other countries, African institutions and regulations are designed to meet the exigencies of central (often mainly thermal) generation. New institutional arrangements are required.

- Consideration of potential complementarities between centralized generation and rural electrification. For example, in West Africa, greater solar potential broadly exists in Savannah and Sahelian zones while population is concentrated to the South along the coast (where cloud cover is frequent). Generation in the North with transmission to the South may (or may not) simultaneously provide reliable power at low cost to the urban zones in the South while offering cheap electrification to towns and small cities, particularly along the transmission path, in the North.
- A renewed emphasis on power pools. While the African continent is vast, it is divided into more than 50 countries. In many parts of the continent, efficient diversification of generation resources would take place across countries implying an even greater role for regional power pools.

- More integrated modeling of water and energy systems in planning to account for competing requirements and opportunities offered, as done in [37-39].

We finish with reflections on implications for the energywater nexus. For some elements of this nexus, the very broad implications of the global energy revolution are relatively clear. For example, inexpensive and distributed electricity implies enhanced ability to pump and treat water, where available. This lays the foundation for lower cost irrigation, water purification, wastewater treatment, and desalinization. This in turn would improve the economics of agriculture and improve access to safe drinking water and sanitation, with large socioeconomic benefits. It is useful to point out that these processes can be engineered to run flexibly in time; hence, they have the potential to contribute to load balancing [23, 24]. Alternatively, they can operate relatively independently functioning when power is being generated and dormant otherwise. On the negative side, unbridled pumping from rivers and aquifers may quickly encounter resource constraints or cause tensions with downstream users.

In other domains, even broad implications are unclear. For example, it is not clear that the transmission infrastructure, institutions, and international cooperation will emerge to take advantage of the hydropower resources on the continent. The role of large-scale hydropower will have implications for large-scale irrigation potentials; the need for which in turn depends on the level of success of the more distributed irrigation systems discussed in the preceding paragraph. The future of bioenergy is also in doubt, depending, for example, on the pace of electrification of the global transport fleet 
(electrification of transport is a second realm where transformation is proceeding at rates vastly exceeding expectations).

In sum, the renewable energy revolution provides valuable tools to enhance growth and development prospects in developing countries, both within Africa and beyond, and meets environmental objectives at global and local scales. Even though water and energy are intertwined, in that one depends on the availability of the other, decision-making in both those sectors is taken in silos. In order to take advantage of the opportunities offered by this energy bonanza, new modeling and planning approaches are required where both energy and water considerations, both on supply and demand, are evaluated within a common framework as done in [37-39].

Accelerated research efforts in that direction and fresh thinking are key inputs to realizing these potentials.

\section{Compliance with Ethical Standards}

Conflict of Interest Channing Arndt, Faaiqa Hartley, Gregory Ireland, Kristi Mahrt, Bruno Merven, and Jarrad Wright declare that they have no conflicts of interest.

Human and Animal Rights and Informed Consent This article does not contain any studies with human or animal subjects performed by any of the authors.

Open Access This article is distributed under the terms of the Creative Commons Attribution 4.0 International License (http:// creativecommons.org/licenses/by/4.0/), which permits unrestricted use, distribution, and reproduction in any medium, provided you give appropriate credit to the original author(s) and the source, provide a link to the Creative Commons license, and indicate if changes were made.

\section{References}

Papers of particular interest, published recently, have been highlighted as:

- Of importance

•. Of major importance

1. EIA. International energy outlook 2017. Washington D.C.: U.S. Energy Information Administration; 2017.

2. IRENA. Solar PV in Africa: costs and markets. Paris: International Renewable Energy Agency; 2016.

3. IRENA. Electricity storage and renewables: costs and markets to 2030. Abu Dhabi: International Renewable Energy Agency; 2017.

4. IRENA. Renewable energy auctions: analysing 2016. Abu Dhabi: International Renewable Energy Agency; 2017.

5. BNEF. New energy outlook 2017. New York: Bloomberg New Energy Finance; 2017.

6. Brinsmead T, Graham P, Hayward J, Ratnam E, Reedman L. Future energy storage trends: an assessment of the economic viability, potential and impacts of electrical energy storage on the NEM 20152035. Newcastle, N.S.W.:CSIRO;2015. CSIRO:EP155039. https:// doi.org/10.4225/08/5852dbcfaffc6.
7. Hoekstra, A. Photovoltaic growth: reality versus projections of the international energy agency. 2017.; https://steinbuch.wordpress. com/2017/06/12/photovoltaic-growth-reality-versus-projectionsof-the-international-energy-agency. Accessed 12 July 2017.

8. AEE Institute. Competitiveness of renewable energy and energy efficiency in U.S. markets. Washington, D.C.: American Energy Economy Institute; 2015.

9. MIT Energy Initiative. The future of solar energy. Cambridge: Massachusetts Institute of Technology; 2015.

10. Odarno L, Sawe E, Swai M, Katyega MJJ, Lee A. Accelerating minigrid deployment in sub-Saharan Africa: lessons from Tanzania. Washington, D.C.: World Resource Institute; 2017.

11. Metayer M, Breyer C, Fell HJ. The projections for the future and quality in the past of the World Energy Outlook for solar PV and other renewable energy technologies. European Photovoltaic Solar Energy Conference, September 14-18, 2015, Hamburg, Germany. 2015. https://doi.org/10.4229/31stEUPVSEC2015-7DV.4.61.

12. Creutzig F, Agoston P, Goldschmidt JC, Luderer G, Nemet G, Pietzcker RC. The underestimated potential of solar energy to mitigate climate change. Nat Energy. 2017;2:17140. https://doi.org/10. 1038/nenergy.2017.140.

13. Arndt C, Hartley F, Ireland G, Mahrt K, Merven B, Wright J. Developments in variable renewable energy and implications for developing countries. Working paper. Pretoria: South Africa Towards Inclusive Economic Development; 2018.

14. REN21. 2017 Renewables global futures report: great debates towards $100 \%$ renewable energy. Paris: REN21 Secretariat.

15. Eberhard A, Naude R. The South African renewable energy independent power producer procurement programme: a review and lessons learned. J Energy South Afr. 2016;27:1-14. https://doi. org/10.17159/2413-3051/2016/v27i4a1483.

16. IEA. Getting wind and sun onto the grid: a manual for policy makers. Paris: OECD/IEA; 2017.

17. IRENA. Planning for the renewable future: long-term modelling and tools to expand variable renewable power in emerging economies. Abu Dhabi: International Renewable Energy Agency; 2017.

18. IRENA. REthinking energy 2017: accelerating the global energy transformation. Abu Dhabi: International Renewable Energy Agency; 2017.

19. IRENA. The power to change: solar and wind cost reduction potential to 2025. Abu Dhabi: International Renewable Energy Agency; 2016.

20. IRENA. Africa power sector: planning and prospects for renewable energy synthesis report. International Renewable Energy Agency: Abu Dhabi; 2015.

21. IRENA. The age of renewable power: designing national roadmaps for a successful transformation. Abu Dhabi: International Renewable Energy Agency; 2015.

22. IEA. Renewable energy: medium-term market report 2016. Paris: OECD/IEA; 2016.

23. Gebretsadik Y, Fant C, Strzepek K, Arndt C. Optimized reservoir operation model of regional wind and hydro power integration. Appl Energy. 2016;161:574-82.

24. Rose A, Stoner R, Pérez-Arriaga I. Prospects for grid-connected solar PV in Kenya: a systems approach. Appl Energy. 2016;161:583-90.

25. Luckow P, Vitolo T, Daniel J. A problem solved: existing measures provide low - cost wind and solar integration. Cambridge: Synapse, Energy Economics; 2015.

26. Hagemann K. Mesoscale wind atlas of South Africa. PhD thesis, Department of Environmental and Geographical Science, University of Cape Town. 2016.

27. Fluri TP. The potential of concentrating solar power in South Africa. Energy Policy. 2009;37:5075-80.

28. WASA. High resolution wind resource maps. Wind atlas of South Africa, South African National Energy Development Institute. 2015, http://wasadata.csir.co.za/wasa1/WASAData. 
29. CSIR, Fraunhofer. Wind and solar resource aggregation study for South Africa. Pretoria: Council for Scientific and Industrial Research; 2016.

30. Wright J, Bischof Niemz T, Calitz J, Mushwana C, van Heerden R, Senatla M. Formal comments on the integrated resource plan (IRP) update assumptions, base case and observations. Pretoria: Council for Scientific and Industrial Research; 2017. This paper provides a comprehensive summary of the technology costs and limitations relevant to South Africa.

31. Mushwana C, Bischof Niemz T, Zimmermann B, Gerlach AK, Bofinger S, Otto M. Smoothing out the volatility of South Africa's wind and solar photovoltaic energy resources. CSIR Science Scope. 2015;8(2):28-9.

32.• Merven B, Ireland G, Hartley F, Arndt C, Hughes A, Ahjum F, Mccall B, Caetano T. Quantifying the macro- and socio-economic benefits of a transition to renewable energy in South Africa. Part 1: the energy landscape. SA-TIED Working Paper. 2018. Pretoria: South Africa - Towards Inclusive Economic Development. This paper assesses the impacts of $\mathbf{R E}$ advances in South Africa using a full sector SATIM energy model and compares the findings to more detailed electricity only models.

33. Reber, TJ, Chartan, EK, Brinkman, GL. Preliminary findings of the South Africa power system capacity expansion and operational modelling study: preprint. United States. 2018. https://www.osti. gov/servlets/purl/1417140. This is the first paper to include high spatial and temporal resolution in a model for South Africa.

34. Wright J, Bischof Niemz T, Calitz J, Mushwana C, van Heerden R, Senatla M. Formal comments on the integrated resource plan (IRP) update assumptions, base case and observations. Pretoria: Council for Scientific and Industrial Research; 2017.

35. Liebreich M. Breaking clean. Presented at the London Summit 2017. Bloomberg New Energy Finance, London, United Kingdom; 2017.

36. IEA. Africa energy outlook: a focus on energy prospects in subSaharan Africa. Paris: OECD/IEA; 2014.

37. Rodriguez D, Delgado A, Bazilian M, Ahjum F, Cullis J, DeLaquil P, Goldstein G, Liden R, Merven B, Miralles-Wilhelm F, Sohns A. Water constrains South Africa's energy future: a case study on integrated energy-water nexus modeling and analysis. The IJES. 2017;6(10):1-25.

38. Alfstad T, Howells M, Rogner H, Ramos E, Zepeda E. Climate, Land-, Energy-, Water-use simulations (CLEWs) in Mauritius-an integrated optimisation approach. InEGU General Assembly Conference Abstracts, Vol. 18; 2016. p. 15765.

39. Bazilian M, Rogner H, Howells M, Hermann S, Arent D, Gielen D, et al. Considering the energy, water and food nexus: towards an integrated modelling approach. Energy Policy. 2011 Dec 1;39(12):7896-906. 